\title{
Qualidade microbiológica do sururu (Mytella charruana) comercializado por catadoras da Baía de Sepetiba, Rio de Janeiro, Brasil ${ }^{*}$
}

\section{Microbiological quality of sururu (Mytella charruana) marketed by scavengers of the Sepetiba Bay, Rio de Janeiro, Brazil}

\author{
Karoline Ribeiro Palmeira, ${ }^{* *}$ Flávia Aline Andrade Calixto, ${ }^{* *}$ Luiz Antonio Moura Keller, ${ }^{* * * *}$ \\ Maria Carmela Kasnowski Duarte Holanda, ${ }^{* * * *}$ Eliana de Fátima Marques de Mesquita******
}

\begin{abstract}
Resumo
A preocupação com a qualidade do pescado é de grande importância para todos, pois é um alimento de alto valor nutritivo, mas tem grande susceptibilidade à deterioração e formação de substâncias prejudiciais à saúde, quando as condições de conservação e manipulação não são mantidas. O cultivo de moluscos bivalves além de ser uma fonte alternativa de alimentos, é uma opção para a subsistência das populações ribeirinhas de todo o litoral, à medida que a matriz alimentícia ganha espaço no mercado, principalmente nas regiões nordeste, sul e sudeste. Os sururus são organismos filtradores, capazes de absorver micropartículas em suspensão, as quais podem carrear elevadas concentrações de microrganismos patogênicos, outro fator importante relacionado a este molusco é a má condição de manipulação no beneficiamento, que pode provocar toxinfecções alimentares, ambos provocando danos à saúde. As análises microbiológicas foram realizadas em sururu in natura e após cozimento. Nas amostras analisadas houve ausência de Salmonella spp., com redução na contagem de Staphylococcus coagulase-positiva e de Coliformes Termotolerantes a $45^{\circ} \mathrm{C}$ nos produtos cozidos. Os resultados são indicativos de que mesmo havendo redução de contaminação bacteriana, a manipulação das catadoras, após cozimento, é inadequada e que medidas corretivas devem ser adotadas para se obter o produto adequado bacteriologicamente ao consumo.
\end{abstract}

Palavras-chave: Coliformes, Mytella charruana, Salmonella sp, sururu.

\begin{abstract}
Fish quality has a great importance concerning to its high nutritional value, due to its great susceptibility to deterioration and occurrence of harmful substances to human health when the storage and handling conditions are not kept properly. The bivalves farming is an alternative source of food and also a source of livelihood for riverside communities, as the product is accepted in the market, mainly in the Northeast, South and Southeast regions. As filter feeders organisms, "sururu" mussels can absorb microparticles which can carry high level of pathogenic micro-organisms. Another important factor is the bad handling conditions both can lead to foodstuff infections. Microbiological analyzes were performed in raw "sururu" mussel and after cooking. The samples analyzed there was no Salmonella sp., a reduction in coagulase-positive Staphylococcus count and thermotolerant coliforms at $45^{\circ} \mathrm{C}$ in baked products. Results of the analyzes showed that even with the contamination reduction, the handling of the women staff after cooking is inadequate and corrective measures should be taken to obtain a safe product for the final consumer.
\end{abstract}

Keywords: Coliform, Mytella charruana, Salmonella sp, "sururu" mussel.

\section{Introdução}

O sururu possui elevada importância econômica para dezenas de famílias ribeirinhas em diferentes estados brasileiros, como forma de subsistência e comercialização do produto; além da importância alimentar, possui grande valor nutricional, rico em proteínas, ácidos graxos poli-insaturados e vitaminas (Lira et al., 2004). Os estuários, local onde é coletado, estão entre os mais produtivos e complexos ecossistemas costeiros do mundo pois agrupam a disponibilidade de água doce, alimentos e a facilidade de transporte (Gianesella e Saldanha-Corrêa, 2010). Nos Estudos desenvolvidos nas últimas décadas, os pesquisadores têm revelado que a pesca artesanal, principalmente a desenvolvida em áreas urbanas, é alvo de problemas ambientais decorrentes, principalmente, da pressão da urbanização irregular, o que tem comprometido a transferência do conhecimento tradicional

*Recebido em 28 de agosto de 2018 e aceito em 21 de novembro de 2018.

**Doutoranda do Programa de Pós-graduação em Higiene Veterinária e Processamento Tecnológico de Produtos de Origem Animal, Universidade Federal Fluminense.

*** Pesquisadora Fundação Instituto de Pesca do Estado do Rio de Janeiro.

****Professor Adjunto do Departamento Zootecnia e Desenvolvimento Agrossocioambiental Sustentável, Universidade Federal Fluminense.

*****Professor Adjunto do Departamento de Tecnologia de Alimentos, Universidade Federal Fluminense.

****** Professor Titular, Departamento de Tecnologia de Alimentos, Universidade Federal Fluminense. 
(Pedrosa et al., 2013). Entre as principais ações antropogênicas que impactam os ecossistemas estuários estão a introdução de espécies invasoras, a pesca predatória e a poluição por esgotos de diversas origens, que contribuem para a diminuição da diversidade e da estabilidade desse ambiente (Troca e Vieira, 2012).

No último panorama sobre o rio Guandu, publicado no Arquivo do Instituto Estadual do Ambiente (INEA), citou-se que o rio Guandu é a principal fonte de abastecimento de água da região metropolitana da cidade do Rio de Janeiro, e deságua na baía de Sepetiba, encontrando-se impactado pelo lançamento de esgotos domésticos, devido a expansão urbana (INEA, 2012).

Segundo Nishida (2008), a prática utilizada para a obtenção dos moluscos é extrativista, estendendo-se geralmente durante todo o ano, não havendo regulamentação institucional-legal por parte dos órgãos ambientais estaduais e/ou municipais para a captura. Embora estudos sobre a biologia dos moluscos, dinâmica da população e efeitos da sobrepesca sejam necessários, os catadores apontam que os estoques desse recurso pesqueiro vêm diminuindo ao longo dos anos.

Por ser um alimento de alto risco e que se encontra largamente associado a surtos alimentares, o monitoramento microbiológico de moluscos, principalmente em áreas de comercialização, fazse necessário (Nascimento et al., 2011). O uso de indicadores de contaminação ambiental e fecal, como a enumeração do grupo coliforme, tem sido amplamente utilizado (Vieira et al., 2008). Surtos de doenças associadas ao consumo de moluscos bivalves foram reportados no mundo todo, sendo que nas últimas três décadas houve aumento dos relatos ocasionados pela ingestão de ostras, seguida de mariscos e mexilhões (Potasman et al., 2002).

Baseado nos fatos descritos objetivou-se na pesquisa em epígrafe avaliar microbiologicamente a qualidade higiênicosanitária do sururu in natura e cozido comercializado pelas catadoras da Baía de Sepetiba, Rio de Janeiro, Brasil.

\section{Material e métodos}

As amostras de sururu, Mytella charruana (ORBIGNY, 1842), oriundas de comunidade pesqueira localizada em Sepetiba, Rio de Janeiro/ RJ, Rio de Janeiro/ RJ, ainda vivas permaneceram com a água do local da coleta, foram acondicionadas em caixas isotérmicas com gelo reciclável para transporte e em seguida levadas para o Laboratório de Controle Microbiológico de Produtos de Origem Animal da Universidade Federal Fluminense (UFF). Esta forma de coleta é utilizada na coleta de vieira, Nodipecten nodosus (LINNAEUS, 1758), pelo Setor de Pesca da Secretaria de Atividades Econômicas da Prefeitura Municipal de Angra dos Reis.

Foram realizadas três coletas, sendo estas nos meses de abril, julho e setembro. Cada coleta realizada foi composta por no mínimo 60 animais adultos vivos, machos e fêmeas, segundo instruções da APHA (APHA, 2001). As amostras vivas foram acondicionadas em caixas isotérmicas com gelo para transporte e em seguida levadas para o Laboratório de Controle Microbiológico de Produtos de Origem Animal do Departamento de Tecnologia dos Alimentos da Faculdade de Veterinária da Universidade Federal Fluminense (UFF).
O cozimento do sururu foi realizado como de rotina pelas catadoras, onde após a retirada do sururu do mangue, o molusco foi transferido para a galéia - espécie de caixote - mergulhado na água lodosa e lavado. Em seguida foi "desimbigado" (processo em que as catadoras soltavam o sururu do lodo), e acondicionado em latões reaproveitados de óleo ou tinta, colocados sobre fogueira, sem nenhum controle de tempo e temperatura, e então ensacado e pesado, para posterior comercialização. A higiene dos utensílios e da manipulação pós-cozimento é precária.

As análises realizadas seguiram o protocolo estabelecido pela Instrução Normativa $n^{\circ}$ 62, de 23 de agosto de 2003, do Ministério Agricultura, Pecuária e Abastecimento (Brasil, 2003) e os resultados se basearam nos padrões microbiológicos estabelecidos pela Resolução $n^{\circ} 12$, de 2 de janeiro de 2001, da Agência Nacional de Vigilância Sanitária - ANVISA(Brasil, 2001). Baseado no descrito anteriormente, preconizou-se analisar Staphylococcus coagulase positiva, coliformes termotolerantes e Salmonella sp.

A contagem de Staphylococcus coagulase positiva foi realizada por espalhamento em placas contendo o meio de cultura Ágar Baird Parker, em seguida foram incubadas em estufa a $37^{\circ} \mathrm{C}$ por 24 - 48 horas e então realizada a leitura. As colônias típicas adquirem coloração preta brilhante com halo claro em torno de suas bordas. As placas selecionadas para leitura continham entre 20 e 200 colônias típicas. Após observação e contagem das unidades formadoras de colônia (UFC) foram realizadas as provas bioquímicas: catalase, DNAse e coagulase (Brasil, 2003).

O Número Mais Provável (NMP) de Coliformes Termotolerantes a $45^{\circ} \mathrm{C}$ foi realizado utilizando três séries de três tubos contendo o meio Fluorocult e incubadas a $35^{\circ} \mathrm{C}$ por 24 horas. Após o período de incubação os tubos que possuíam coloração verdeazulada foram considerados positivos para o crescimento de coliformes, após observação em câmara escura com luz ultravioleta de 366nm. A combinação dos tubos positivos para coliformes foi analisada na tabela de McCrady obtendo-se o NMP (Brasil, 2003).

A pesquisa de Salmonella spp., foi realizada utilizando-se etapas de enriquecimento, plaqueamento seletivo. No enriquecimento os meios utilizados foram Rappaport Vassiliadis e Mossel, no plaqueamento seletivo foram utilizados os meios Rambach, Hektoen e Xilose Lisina Desoxicolato (XLD). (Brasil, 2003). A triagem e o perfil bioquímico, não foram realizados, pois não houve presença de colônias suspeitas de Salmonella sp. (Brasil, 2003).

\section{Resultados e discussão}

Apesar da composição química e das vantagens e benefícios, o consumo de bivalves possui riscos que estão relacionados a quantidade de contaminantes presentes nos locais onde os moluscos bivalves habitam, sendo que os contaminantes podem ser biológicos e químicos (Cabral, 2015). Por ser realizado em um ambiente com progressivo grau de degradação ambiental, além de extremamente desgastante, a coleta do sururu possui a inerente insalubridade intensificada. O tipo de alimentação destes animais, por filtração, acaba por ser o principal responsável pela sua vulnerabilidade à contaminação (Castilho, 2010). Sabe-se que os moluscos são consumidos inteiros (não- 
eviscerados) e parcialmente cozidos (pois se forem submetidos a um prolongado tempo de cozimento ficam com consistência endurecida e tornam-se desagradáveis ao paladar), o risco de contágio por agentes patogênicos aumenta, por não serem totalmente eliminados pela temperatura e tempo de cozimento (Cabral, 2015).

Os locais de beneficiamento do sururu geralmente são abertos, com animais e insetos circulando e não existe higiene durante a manipulação, como o lavar as mãos e usar toucas, colocando em risco a saúde do consumidor. A maioria dos manipuladores desconhece a possibilidade de serem portadores assintomáticos de microrganismos e utilizam práticas inadequadas de higiene. Além disso, o sururu é geralmente comercializado à temperatura ambiente, o que contribui para uma rápida proliferação de microrganismos (Delgado da Silva et al., 2002).

Em conformidade com a ANVISA (Brasil, 2001), na legislação consta que Salmonella spp. seja ausente, que a contagem total de Staphylococcus coagulase positiva não seja superior a $10^{3} \mathrm{UFC} / \mathrm{g}$ para moluscos bivalves in natura e cozidos e que o NMP de Coliformes termotolerantes a $45^{\circ} \mathrm{C}$ não ultrapasse $5 \times 10$ UFC/g no produto cozido, não havendo padrão para as matrizes alimentícias pesquisadas in natura. As amostras in natura estavam acima do padrão na contagem de Staphylococcus coagulase positiva e também após o cozimento. O NMP de coliformes termotolerantes a $45^{\circ} \mathrm{C}$ do sururu cozido também estavam acima do preconizado pela ANVISA (Tabela 1). Mesmo havendo ausência de Salmonella spp., interpretando-se os resultados observados os analitos pesquisados, são indicativos de que há necessidade de ações corretivas desde o treinamento das catadoras até o tratamento térmico adequado da matéria prima. A presença de coliformes termotolerantes a $45^{\circ} \mathrm{C}$, coliformes e Staphylococcus coagulase positiva, em alimentos processados é considerada indicativa de contaminação pós-processamento ou processamento térmico inadequado, evidenciando práticas higiênicas inadequadas. Há necessidade de aperfeiçoamento nas condições de beneficiamento do sururu para obtenção de matrizes alimentícias inócuas para evitar riscos à saúde do consumidor.

Tabela 1: Avaliação microbiológica (UFC/g) do sururu oriundo da Baia de Sepetiba

\begin{tabular}{llll}
\hline Amostra/Análises & $\begin{array}{l}\text { Sururu in } \\
\text { natura }\end{array}$ & $\begin{array}{l}\text { Sururu } \\
\text { cozido }\end{array}$ & $\begin{array}{l}\text { ANVISA } \\
(2001)\end{array}$ \\
\hline Staphylococcus coagulase positiva & $2,4 \times 10^{3}$ & $3,3 \times 10^{2}$ & $10^{3}$ \\
Coliformes Termotolerantes a $45^{\circ} \mathrm{C}$ & $3,0 \times 10^{5}$ & $7,5 \times 10^{3}$ & $5 \times 10$ \\
Salmonella spp. & Ausência & Ausência & Ausência \\
\hline UFC/g: Unidade Formadora Cônia/grama & &
\end{tabular}

UFC/g: Unidade Formadora de Colônia/grama

Organismos filtradores, como ostras, sururus e mexilhões, podem concentrar e bioacumular micro-organismos, inclusive aqueles patogênicos, em seus tecidos, quando cultivados ou extraídos de locais contaminados (Martinez e Oliveira, 2010; Doi et al., 2014). Dentre os agentes biológicos envolvidos na contaminação de alimentos estão bactérias, vírus e parasitas, que podem causar distúrbios que vão desde gastroenterite leve até casos mais sérios que podem levar o indivíduo à morte. Alguns desses patógenos estão presentes naturalmente no ambiente aquático, enquanto outros podem ser introduzidos a partir de esgoto lançado no ambiente (Amagliani et al., 2012).

Em 2012, foi instituído o Programa Nacional de Controle Higiênico-Sanitário de Moluscos Bivalves (PNCMB), no Ministério da Pesca e Aquicultura (MPA) pela Instrução Normativa Interministerial $n^{\circ} 7$, o com a finalidade de estabelecer os requisitos mínimos necessários para a garantia da inocuidade e qualidade dos moluscos bivalves destinados ao consumo humano, bem como monitorar e fiscalizar o atendimento destes requisitos. No PNCMB são abrangidas as etapas de retirada, trânsito, processamento e transporte de moluscos bivalves destinados ao consumo humano. O monitoramento de microrganismos contaminantes em moluscos bivalves é estabelecido por meio da estimativa de Escherichia coli em 100 gramas da parte comestível dos moluscos bivalves (NMP/100g), sendo liberada a retirada de moluscos bivalves quando NMP para E. coli é menor que 230 , a liberação sob condição é realizada quando o NMP está entre 230 e 46.000 e acima de 46.000 a retirada é suspensa.

Assim como na Instrução Normativa Interministerial $n^{\circ} 7$, na Portaria $n^{\circ} 204$, de 28 de junho de 2012, foram estabelecidos os procedimentos para coleta de amostras destinadas a realização de análises de micro-organismos contaminantes e de toxinas em moluscos bivalves e de análises para o monitoramento de espécies de microalgas potencialmente produtoras de toxinas, bem como, a definição das metodologias analíticas oficiais que deverão ser adotadas pela Rede Nacional de Laboratórios do MPA para estas análises (Brasil, 2012). No entanto, o elevado custo deste monitoramento, a falta de previsão da origem orçamentária para custeá-las e o tempo elevado para realização de algumas das análises previstas, pode inviabilizar a averiguação (Horodesky, 2014).

A legislação brasileira difere da legislação europeia quanto ao controle da retirada de moluscos. Na europeia classificam-se as zonas de produção, e na brasileira, a condição da retirada. Porém, na prática, a aplicação desses conceitos é similar, com a definição de classes que restringem o aproveitamento dos moluscos com base em resultados de monitoramento de parâmetros microbiológicos em amostras dos bivalves provenientes das zonas de produção ou extração (Epagri, 2014). Na legislação brasileira é estabelecida que as coletas sejam realizadas de cinco amostras de moluscos obtidas em um mesmo dia e de diferentes pontos de coleta em uma mesma área de extração ou cultivo (Coelho et al., 2003), já na legislação europeia não é estabelecido um número de amostras a ser realizado no mesmo local e no mesmo dia (por padrão, sendo feita uma única amostra), porém considera-se a série histórica de até três anos de dados microbiológicos para a definição da classificação da zona de cultivo ou extração de moluscos (Coelho et al., 2003). Baseando-se na legislação europeia sugere-se que a estratégia de coleta seja mais segura do ponto de vista da saúde pública.

$\mathrm{Na}$ legislação europeia são determinadas três classes para a classificação das zonas de produção e extração de moluscos, conforme apresentado na Tabela 2. 
Tabela 2: Padrões microbiológicos para a classificação das zonas de produção de moluscos em vigor na União Europeia

\begin{tabular}{|c|c|c|}
\hline Classe & Padrão microbiológico & Tratamento pós-coleta \\
\hline A & $\begin{array}{l}\text { Moluscos vivos dessas áreas não } \\
\text { podem exceder a } 230 \mathrm{NMP}^{1} \text { de } E \text {. } \\
\text { coli por } 100 \mathrm{~g} \text { de carne e líquido } \\
\text { intravalvar }\end{array}$ & $\begin{array}{l}\text { Moluscos podem ser apanhados } \\
\text { e comercializados para consumo } \\
\text { humano direto }\end{array}$ \\
\hline B & $\begin{array}{l}\text { Moluscos vivos dessas áreas não } \\
\text { podem exceder a } 4.600 \text { NMP de } \\
E \text {. coli por } 100 \mathrm{~g} \text { de carne e líquido } \\
\text { intravalvar }\end{array}$ & $\begin{array}{l}\text { Moluscos podem ser } \\
\text { comercializados desde que } \\
\text { sujeitos previamente a depuração, } \\
\text { relocação ou tratamento térmico em } \\
\text { unidade industrial }\end{array}$ \\
\hline C & $\begin{array}{l}\text { Moluscos vivos dessas áreas não } \\
\text { podem exceder a } 46.000 \text { NMP de } \\
E \text {. coli por } 100 \mathrm{~g} \text { de carne e líquido } \\
\text { intravalvar }\end{array}$ & $\begin{array}{l}\text { Moluscos podem ser } \\
\text { comercializados desde que } \\
\text { sujeitos previamente a relocação } \\
\text { prolongada ou tratamento térmico } \\
\text { em unidade industrial }\end{array}$ \\
\hline PROIBIDA $^{2}$ & $\begin{array}{l}>46.000 \text { NMP de E. coli por } 100 \mathrm{~g} \\
\text { de carne e líquido intravalvar }\end{array}$ & Coleta não permitida \\
\hline
\end{tabular}

\footnotetext{
(1) NMP = número mais provável.

(2) Essa classe não é mencionada especificamente na legislação. Contudo, a autoridade competente tem legitimidade para proibir a retirada de moluscos em áreas de cultivo consideradas impróprias por razões de proteção da saúde pública.
}

Fazendo uma comparação, verifica-se que na legislação brasileira é mais permissiva, uma vez que permite que áreas onde uma amostra de moluscos com resultados de até 46.000 E. coli/100g (as demais devem ter valores inferiores a 230 E. coli/100g) possam comercializar bivalves sem tratamento para redução de carga microbiana. Além disso, moluscos provenientes de retirada definida como "Liberada sob condição" (resultados de até 46.000 E. coli/100g) podem ter sua carga microbiana reduzida por meio de tratamentos pós- coleta como depuração em ambiente controlado ou tratamento térmico. $\mathrm{Na}$ legislação europeia restringem-se a adoção da depuração em ambiente controlado como tratamento pós-coleta de moluscos provenientes de áreas $\mathrm{B}$, exigindo tratamentos mais restritivos para a classe $\mathrm{C}$.

Silva et al. (2015) encontrou valor incontável de coliformes termotolerantes em $100 \%$ das amostras de sururu comercializados em um mercado público de Maceió (Alagoas). Resultado semelhante foi descrito por Mafra et al. (2016) que ao analisar coliformes termotolerantes em sururu processado e comercializado em Maragogipe (Bahia), todas as amostras analisadas estavam acima do estabelecido conforme RDC $n^{\circ}$ 12 (Brasil, 2001). Ainda segundo o mesmo autor, o sururu foi o molusco em que foi encontrado maior densidade microbiana, quando comparado ao "chumbinho" (Anomalocardia brasiliana) e a tarioba (Iphigenia brasiliana) também analisados no na pesquisa.

\section{Referências}

AMAGLIANI, G.; BRANDI, G.; SCHIAVANO, G.F. Incidence and role of Salmonella in seafood safety. Food Research International, v.45, n.2, p.780-788, 2012.
Em estudo realizado por Nascimento et al. (2011) amostras de sururu e ostras foram analisadas in natura, congelados à $-18^{\circ} \mathrm{C}$ e após tratamento térmico à temperatura de $95^{\circ} \mathrm{C}$. Em relação aos coliformes totais e termotolerantes a maioria das amostras de sururu e ostras adquiridas desconchadas foi encontrado NMP maior que $1,6 \times 10^{3} / \mathrm{g}$, não havendo redução da carga microbiana durante a estocagem congelada, mantendo-se fora dos padrões de qualidade microbiológica. Além disto, verificou-se a presença de colônias típicas de Escherichia coli e de Salmonella sp. em todas as amostras analisadas. Após o précozimento a contaminação por coliformes termotolerantes foi menor que 3,0 NMP/g e verificou-se ausência de Salmonella spp. em todos os tempos de pré-cozimento estudados. Baseando-se nos resultados encontrados sugere-se que o tratamento térmico, quando realizado em condições de higiene e de forma eficiente, diminuiu a microbiota inicial.

Em relação ao Staphylococcus coagulase positiva, a contaminação dos moluscos bivalves é geralmente associada à falta de higiene durante a manipulação e comercialização do pescado (Alves et al., 2002). Dentre as espécies capazes de produzir a coagulase, Staphylococcus aureus é o principal patógeno humano, responsável pelas infecções hospitalares e comunitárias (Bien et al., 2011).

Porfírio et al. (2014) não encontraram S. aureus como contaminantes do sururu beneficiado comercializado na cidade de Maceió, resultado semelhante ao encontrado por Farias et al. (2010) que ao analisarem o molusco unha-de-velho (Tagelus plebeius) provenientes do estuário do rio Ceará, em Fortaleza (Ceará) não detectaram a presença de Staphylococcus coagulase positiva nas amostras. Entretanto Galvão et al. (2006) ao avaliarem as condições de mexilhões provenientes de Ubatuba (SP) encontraram resultados divergentes, onde parte das amostras encontraram-se fora dos padrões.

Segundo Normanno et al. (2005), o controle da contaminação por Staphylococcus spp. pode ser realizada através do cumprimento, incluindo o cuidado na manipulação em todo o processamento do alimento, desde o cozimento até a estocagem imediata a temperaturas inferiores a $7^{\circ} \mathrm{C}$.

\section{Conclusões}

A qualidade microbiológica das amostras de sururu in natura e cozido analisadas estava insatisfatória sendo indicativa de condições inadequadas de higiene durante o processamento.

APHA. Standard methods for the examination of water and wastewater. In). Washington: 20. ed. American Public Health Association, American Water Works Association, and Water Pollution Control Federation, 2001. Balamatsia, C. C., Paleologos, E. K., Kontominas, M. G., \& SAPHA, 2001. 
BIEN, J.; SOKOLOVA, O.; BOZKO, P. Characterization of virulence factors of Staphylococcus aureus: novel function of known virulence factors that are implicated in activation of airway epithelial proinflammatory response. Journal of pathogens, v. 2011, 2011

BRASIL. RESOLUÇÃO - RDC n. 12, de 02 de janeiro de 2001. Regulamento técnico sobre Padrões Microbiológicos para Alimentos. Diário Oficial da União, Brasília, 02 de janeiro de 2001. BRASIL. INSTRUÇÃO NORMATIVA n. 62, de 26 de agosto de 2003. Anexo I - Métodos analíticos oficiais para análises microbiológicas para controle de produtos de origem animal e água. Diário Oficial da União, Brasília, 18 de setembro de 2003, seção 1, p. 14.

BRASIL. PORTARIA n. 204, de 28 de junho de 2012. Diário Oficial da União, Brasília, 29 junho de 2012, seção 1, p. 56.

BRASIL. INSTRUÇÃO NORMATIVA INTERMINISTERIAL n. 07 de 08 de maio de 2012. Programa Nacional de Controle Higiênico-Sanitário de Moluscos Bivalves. Diário Oficial da União, Brasília, 09 de maio de 2012, seção 1, p. 55-59.

CABRAL, M.L. Avaliação da contaminação microbiológica e da resposta ao stress ambiental em moluscos bivalves da Ria Formosa. 2015. 57 f. Dissertação (Mestrado) -Instituto Superior de Engenharia - Universidade do Algarve, Algarve, 2015.

COELHO, C.; HEINERT, A.P.; SIMÕES, C.M.O.; BARARDI, C.R.M. Hepatitis A virus detection in oysters (Crassostrea gigas) in Santa Catarina State, Brazil, by reverse transcription polymerase chain reaction. Journal of Food Protection, v.66, n.3, p.507-511, 2003.

COELHO, C.; VINATEAI, C.E.B.; HEINERT, A.P.; SIMÕES, C.M.O.; BARARDI, C.R.M. Comparison between specific and multiplex reverse transcription-polymerase chain reaction for detection of hepatitis A virus, poliovirus and rotavirus in experimentally seeded oysters. Memórias do Instituto Oswaldo Cruz, n.98, v.4, p.465-468, 2003.

DELGADO da SILVA, M.C.; NORMANDE, A.C.L.; FERREIRA, M.V.; RAMALHO, L.S. Avaliação da Qualidade Microbiológica de Pescado Comercializado em Maceió, AL. Higiene Alimentar, v.16, n.1, p. 61-65, 2002.

DOI, S.A.; BARBIERI, E.; MARQUES, H.L.A. Densidade colimétrica das áreas de extrativismo de ostras em relação aos fatores ambientais em Cananeia (SP). Engenharia Sanitária e Ambiental, v.19, n.2, p. 165-171, 2014.

FARIAS, M.F.; ROCHA-BARREIRA, C.A.; CARVALHO F.C.T.; SILVA, C.M.; REIS, E.M.F.; COSTA, R.A.; VIEIRA, R.H.S.F. Condições microbiológicas de Tagelus plebeius (LIGHTFOOT, 1786) (MOLLUSCA: BIVALVIA: SOLECURTIDAE) e da água no estuário do rio Ceará, em Fortaleza-CE. Boletim Instituto de Pesca, v.36, n.2, p.135-142, 2010.

GALVÃO, J.A.; FURLAN, E.F.; SALÁN, E.D.O.; PORTO, E.; OETTERER, M. Características físico-químicas e microbiológicas (Staphylococcus aureus e Bacillus cereus) da água e dos mexilhões cultivados na região de Ubatuba, SP. Ciência agrotec, v.30, n.6, p.1124-1129, 2006.

HORODESKY, A. Legislação para produção e comercialização de ostras no litoral paranaense. 2014. Disponível em: http:// www.gia.org.br/m\%C3\%ADdia-e-pr\%C3\% AAmios/videos/ problemas-na-ostreicultura/19-not\%C3\%ADcias/204legisla\%C3\%A7 \%C3\%A3o-para-produ\%C3\%A7\%C3\%A3o-ecomercializa\%C3\%A7\%C3\%A3o-de-ostras-no-litoral-paranaense. Visualizado em: 31 de outubro de 2016.

INEA - INSTITUTO ESTADUAL DO AMBIENTE. Panorama da Qualidade das Águas Superficiais do Brasil 2012. 2012. Disponível em: http://arquivos.ana.gov.br /imprensa/publicacoes/ Panorama_Qualidade_Aguas_Superficiais_BR_2012.pdf. Visualizado em: 06 de novembro de 2016.
LIRA, G.M.; MANCINI FILHO, J.; SANT'ANA, L.S.; TORRES, R.P.; OLIVEIRA, A.C.; OMENA, C.M.B.; SILVA NETA, M.L. Perfil de ácidos graxos, composição centesimal e valor calórico de moluscos crus e cozidos com leite de coco da cidade de Maceió-Al. Revista Brasileira de Ciências Farmacêuticas, v.40, n.4, p.529- 537, 2004.

MAFRA, J.F.; MARQUES, V.F.; CARNEIRO, C.S.; OLIVEIRA, T.A.S.; EVANGELISTA-BARRETO, N.S. Avaliação da qualidade microbiológica de moluscos bivalves processados e comercializados em Maragogipe, estado da Bahia, Brasil. Acta of Fisheries and Aquatic Resources, v.4, n.2, p.39-43, 2016.

MARTINEZ, D.I.; OLIVEIRA, A.J.F.C. Faecal bacteria in Perna perna (Linnaeus, 1758) (Mollusca: Bivalvia) for biomonitoring coastal waters and seafood quality. Brazilian Journal of Oceanography (Impresso), v.58, n.3, p.25-35, 2010.

NASCIMENTO, V.A.; MITTARAQUIS, A.S.P.; TRAVÁLIA, B.M.; SANTOS, R.C.A.; NUNES, M.L.; AQUINO, L.C.L. Qualidade microbiológica de moluscos bivalves - sururu e ostras submetidos a tratamento térmico e estocagem congelada. Scientia Plena, v.7, n.4, p.1-5, 2011.

NISHIDA, A.K.; NORDI, N.; ALVES, R.R.N. Aspectos socioeconômicos dos catadores de moluscos do litoral paraibano, Nordeste do Brasil. Revista de Biologia e Ciências da Terra, v.8, n.1, p.207-215, 2008.

NORMANNO, G.; FIRINU, A.; VIRGILIO, S.; MULA, G.; DAMBROSIO, A.; POGGIU, A.; DECASTELLIC, L.; MIONID, R.; SCUOTAE, S.; BOLZONIF, G.; DI GIANNATALEG, E.; SALINETTIH, A.P.; LA SALANDRAI, G.; BARTOLIJ, M.; ZUCCONB, F.; PIRINOB, T.; SIASB, S.; PARISII, A.; QUAGLIAA, N.C.; CELANOA, G.V. Coagulase-positive Staphylococci and Staphylococcus aureus in food products marketed in Italy. International Journal of Food Microbiology, v.98, n.1, p.73-79, 2005.

PEDROSA, B.M.J.; LIRA, L.; MAIA, A.L.S. Pescadores urbanos da zona costeira do Estado de Pernambuco, Brasil. Boletim do Instituto de Pesca, v.39, n.2, p.93- 106, 2013.

PORFÍRIO, Z.; DA ROCHA, L. P.; TELES, J. A. A.; MARTINS, A. N.; ALMEIRDA, L. D. L.; DA ROCHA MALTA, C. R. Avaliação microbiológica de amostras beneficiadas do sururu (Mytella charruana Orbigny, 1942) (mollusca: bivalvia) na cidade de Maceió, Alagoas. Revista de Educação Continuada em Medicina Veterinária e Zootecnia, v.12, n.1, p.92-93, 2014.

POTASMAN, I.; PAZ, A.; ODEH, M. Infectious outbreaks associated with bivalve shellfish consumption:a worldwide perspective. Clinical Infection Diseases, v.35, n.8, p.921-928, 2002.

SILVA, A.A.V.; COSTA, A.F.M.; FREITAS, R.M.S.; SANTOS, M.B.S.V.; LOURENÇO, A.L.N.; MALTA, A.S.; FIREMAN, A.L.; FERREIRA, D.S.; ROHRIG, L.; SANTOS, S.C.; NOÉ, P.V.R.; SILVA, C.H.B.; SOUZA, E.C.; ROCHA, T.J.M. Qualidade parasitológica e condições higiênico-sanitárias de sururu (Mytella charruana) e alface (Lactuca sativa) comercializados em um mercado público de Maceió-AL. Revista de Ciências Farmacêuticas Básica e Aplicada, v.36, n.4, p.525-529, 2015.

TROCA, D.F.A.; VIEIRA, J.P. Potencial invasor dos peixes não nativos cultivados na região costeira do Rio Grande do Sul, Brasil. Boletim do Instituto de Pesca, v.38, p.2, p.109-120, 2012.

VIEIRA, R.H.S.F.; ATAYDE, M.A.; CARVALHO, E.M.R.; CARVALHO, F.C.T.; FONTELES FILHO, A.A. Contaminação fecal da ostra Crassostrea rhizophorae e da água de cultivo do estuário do Rio Pacoti (Eusébio, Estado do Ceará): isolamento e identificação de Escherichia coli e sua susceptibilidade a diferentes antimicrobianos. Brazilian Journal of Veterinary Research and Animal Science, v.45, n.3, p.180-189, 2008. 